\title{
CONSTRUÇÃO DE UM GLOSSÁRIO EM LIBRAS DA CIDADE DE VILHENA: PRODUÇÃO DE EFEITOS DE SENTIDOS NOS ALUNOS SURDOS \\ ****
}

\section{CONSTRUCTION D'UN GLOSSAIRE EN LANGUE DES SIGNES DE LA VILLE DE VILHENA: PRODUCTION DE SENS CHEZ LES ÉLÈVES SOURDS.}

Recebimento do texto: $22 / 04 / 2018$

Marta de Paula Vieira ${ }^{1}$ Data de aceite: $25 / 05 / 2018$

RESUMO: Este trabalho, desenvolvido no Mestrado Profissional em Letras - ProfLetras Cáceres - MT da Universidade do Estado de Mato Grosso - UNEMAT, apresenta uma proposta didático-pedagógica desenvolvida com os alunos surdos do $9^{\circ}$ ano da Escola Estadual de Ensino Fundamental e Médio Marechal Rondon, em Vilhena - RO. O projeto objetivou a nomeação, em Língua Brasileira de Sinais (Libras), de locais da cidade de Vilhena e como produto deste trabalho, a produção de um glossário. Pelo viés dos estudos semânticodiscursivos, a pesquisa fundamentou-se na Semântica do Acontecimento, de Eduardo Guimarães, em articulação com a Análise de Discurso, instituída por Michel Pêcheux, na França, e Eni Orlandi, no Brasil, e a História das Ideias Linguísticas.

PALAVRAS-CHAVE: Glossário; Libras; Nomeação; Análise de Discurso; Saber Urbano e Linguagem.

RESUMÉ: Ce travail, élaboré lors de la Maîtrise Professionnelle en Lettres - ProfLetras Cáceres/MT, Université de l'Etat du Mato Grosso/UNEMAT, présente une proposition didactico-pédagogique développée avec les élèves malentendants de la 9ème année de l'école publique d'enseignement primaire et secondaire Marechal Rondon, à Vilhena-RO. Le projet a pour but de nommer des lieux de la Ville de Vilhena en langue des signes brésilienne (Libras) et en conséquence de ce travail, la production d'un glossaire. Par le biais d'études discursives, la recherche s'appuie sur la Semântica do Acontecimento (Sémantique de l'évènement) d'Eduardo Guimarães en articulation avec l'Analyse du discours de Michel Pêcheux en France et Eni Orlandi au Brésil avec l'História das Ideias Linguísticas (Histoire des Idées Linguistiques).

MOTS-CLÉS: Glossaire; Libras; Dénomination; Analyse de discours; Connaissance urbaine et langage.

\footnotetext{
${ }^{1}$ Doutoranda do Programa de Pós-Graduação em Linguística da UNEMAT/Cáceres-MT.

${ }^{2}$ Doutora em Linguística pela UNICAMP. Docente do Curso de Letras e do Programa de Mestrado Profissional em Letras/ProfLetras da UNEMAT/Cáceres-MT. E-mail: nilcem@unemat.br
} 


\section{Introdução}

A educação de surdos tem sido amplamente debatida no Brasil. Trata-se de um longo percurso que pode ser exemplificado por diferentes acontecimentos como a criação do Collégio Nacional para Surdos-Mudos no Rio de Janeiro, por Ernest Huet, em 1857, atual Instituto Nacional de Educação de Surdos - INES; a oficialização da Lei no 10.436, a "Lei da Libras", em 2002 e ao recente debate promovido pelo tema da redação do Enem 2017: "Desafios para a formação educacional de surdos no Brasil".

Compreendemos que educar em Libras é também propor materialidades significantes em Libras que proporcionem aos alunos conhecimento de língua e sobre a língua. Flausino da Gama inaugura, em 1857, com a "Iconographia dos Signaes dos Surdos-Mudos", a produção de dicionários e glossários em Língua de Sinais no Brasil. Os glossários objetivam auxiliar na educação de surdos, além de registrar e expandir os sinais da Língua de Sinais.

No trabalho que desenvolvemos com os alunos surdos buscamos criar condições para que o aluno conheça os sinais dos locais da cidade de Vilhena, já consolidados pela comunidade surda, e nomeasse os locais da cidade que ainda não possuem um sinal em Libras. O trabalho também buscou compreender que os dicionários não são somente objetos detentores dos sentidos "neutros" das palavras, mas, produzem sentidos sobre a língua e os sujeitos, no movimento da história e da sociedade. A turma escolhida para o desenvolvimento do 
projeto é composta por 7 alunos surdos que cursam a série numa sala denominada bilíngue. Buscamos por meio da leitura discursiva dos dicionários, mapas, fotografias e documentários proporcionar aos alunos surdos condições de compreender como a cidade se constitui pelos diversos discursos apresentados.

quando tomamos a nomeação de construções urbanas como lugar de reflexão, podemos dizer que a produção de uma referência no espaço tem a ver com a simbolização desse espaço: o modo como um nome (se) projeta (em) outros, identificando o espaço e recortando uma sua memória. (FEDATTO, 2013, p. 114)

As diferentes materialidades trabalhadas com os alunos ampliaram as possibilidades de interpretações ante às diversas interpretações possíveis. Conhecer a cidade e produzir saber na Língua de Sinais possibilita um redimensionamento nas práticas em sala de aula, movendo, imaginariamente, esse espaço físico. Essas leituras discursivas proporcionam deslocamentos de sentidos em relação ao ser professora de língua.

\section{Conhecendo Vilhena: leitura de mapas, ruas, praças}

Na busca pelo saber da língua e saber a língua, a Libras e a Língua Portuguesa circulam, em intensa disputa, no espaço escolar. Dentre os muitos espaços de circulação das línguas, a escola é um espaço privilegiado, por ser um "espaço de relações de sentidos que investem nos sujeitos formas e gestos de interpretação muito

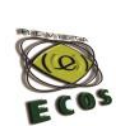


específicos, que conformam suas relações sociais”. (PFEIFFER, 2011, p. 253).

A partir da compreensão da importância dos materiais em Libras, do aspecto visual da língua e das necessidades que foram surgindo durante a intervenção, redirecionei as atividades para exploração de mapas. Guimarães (2005, p. 59) diz que “Tomar o mapa como texto é considerá-lo como linguagem" repleta de sentidos. Recortamos para esse artigo, algumas atividades com leituras de mapas e listas telefônicas da cidade de Vilhena. Ao fazer este recorte, nos reportamos a Orlandi $(2011$, p. 31) que nos diz que "O mapa não é só um esboço no papel. É traçado da memória. É percurso de sentidos. Tem historicidades. Materialidade discursiva".

Enquanto trabalhávamos as listas de lugares para a construção do glossário, percebia o desconhecimento dos alunos com relação aos nomes dos lugares da cidade. Alguns alunos se locomoviam pela cidade sozinhos, normalmente de bicicleta e, portanto, conheciam diversos lugares distantes ou próximos. Outros apenas saíam com os pais. Embora situações comuns a qualquer adolescente, o nome desses espaços era desconhecido. Embora desconhecessem os nomes próprios dos lugares, alguns não demonstravam dificuldades de localização.

Organizei estas atividades de leituras de mapas, levando para a sala de aula o mapa da cidade de Vilhena. Na sala havia um mapamúndi, um mapa de político do Brasil com os sinais dos estados e das capitais, em Libras, e um mapa político do estado de Rondônia. Na 
escola não havia mapa da cidade de Vilhena, por isso adquiri dois mapas da cidade. Os mapas mediam cerca de $0,80 \mathrm{~cm}$ de largura por 1 metro de comprimento. Os alunos não conheciam o mapa da cidade e se surpreenderam ao perceber as distâncias entre os bairros em que residiam e a escola, além de distâncias entre outros lugares. Também observaram os tamanhos dos bairros, os formatos dos limites de bairro, os espaços mais e menos povoados. Alguns alunos já apontavam lugares que frequentavam e conheciam e outros tinham dificuldade em localizar alguns espaços da cidade nos mapas, como a casa deles, as igrejas que frequentavam, algumas escolas. Alguns alunos sinalizavam estabelecimentos comerciais, escolas e referências na cidade, mas desconheciam os sinais próprios das ruas, avenidas e bairros.

Três alunos conheciam o mapa de Rondônia e os nomes e sinais de algumas cidades do estado bem como sua localização. Mostraram-se interessados e hábeis nas leituras dos mapas. Os demais tiveram dificuldades em localizar no mapa do estado a cidade onde moramos. Fizemos leituras no mapa do estado a fim de reconhecermos algumas cidades. Fui indicando e sinalizando e pesquisando com os alunos se conheciam alguns pontos turísticos de outras cidades, questionando quais locais que já tinham visitado ou conheciam e pedia que sinalizassem esses locais.

Alguns alunos foram para o mapa do Brasil e localizaram algumas cidades para as quais tinham viajado. Dois alunos foram para 
o mapa mundial ora perguntando sobre os países, culturas, clima, ora sugerindo uma futura viagem.

Impelidos pela curiosidade dos alunos, fomos ao mapa do mundo. Eles sinalizaram vários países ou características culturais, naturais, entre outros. Surgiram perguntas que retomavam desde a Pangeia às Grandes Navegações. Fizemos também um percurso no mapa do Brasil. Indiquei onde nasci e alguns lugares por onde viajei. Falei sobre a migração de muitos sulistas, que vieram para Rondônia e que tal processo incluía vários parentes dos alunos. Os que conheciam outros estados indicaram os locais. Guimarães (2005, p. 60) nos diz que "um mapa, por mais que ele se dê como descrição de um espaço, é antes uma indicação de acessos ao mundo do que uma descrição".

Fizemos uma ampla exploração no mapa de Rondônia, listando e sinalizando as cidades e procurando um ponto turístico ou algo marcante para ilustrar o município do estado indicado no mapa. Só após esses percursos, conseguimos nos fixar no mapa de Vilhena. Nas leituras deste mapa, identificamos o centro, as principais escolas, as igrejas, praças e outros locais.

Durante a atividade com mapas, percebendo a expansão da cidade, os loteamentos novos e outras particularidades, observamos que a atividade dá visibilidade ao que nos diz Rodríguez-Alcalá (2003, p. 78):

o que está em jogo é a relação estabelecida pelo homem com a natureza [...] que é uma relação de transformação: o homem cultiva o espaço em que vive seu espaço de vida é resultado desse trabalho de transformação. O 

construído a partir do seu trabalho sobre aquele. Entre o homem e o meio natural há uma mediação necessária e intransponível, que é a condição da vida humana.

Havia pedido aos alunos, anteriormente, para trazerem o endereço residencial por escrito, já que apenas dois alunos sabiam informar o endereço onde moravam. Localizamos a casa de cada um num mapa maior afixado na lousa. Essa atividade foi altamente produtiva e os alunos se aglomeravam frente à lousa, indicando no mapa e compartilhando experiências.

Percebemos que esta era uma alternativa interessante para o conhecimento dos locais da cidade, mas o tamanho e a escassez de mapas interferiam negativamente na exploração, de forma coletiva. Então, recolhemos, em casa, na escola e junto aos colegas listas telefônicas da cidade. Levamos para cada aluno uma agenda telefônica da cidade, que contém nas páginas iniciais um mapa da cidade e eles foram localizando suas residências nesses mapas. Depois todos apontavam para os colegas a localização da casa deles no mapa maior. Também pedimos que localizassem um ponto de referência, um local público, conhecido próximo a casa deles. Objetivava que os alunos reconhecessem que todos os espaços da cidade, públicos e privados, faziam parte de um todo: a própria cidade. Era necessário que os alunos compreendessem que esses espaços são habitados por sujeitos distintos. Lemos em Guimarães (2005, p. 60) que 
Como descrição de uma cidade um mapa seria uma imitação grosseira. Como narração, contaria uma história de épocas diferentes como sucessões que se projetaram em contiguidades progressivas. E só. Como instrução, não sendo nenhuma coisa e nem outra, ele é sentido que pode nos dizer mais, tanto do retrado como da história da cidade, do que se fosse diretamente descrição e narração.

Durante essa atividade, alguns alunos, observando o mapa, indicaram o local de uma chácara que frequentavam no fim de semana. Em meio à conversa sobre rios e cachoeiras da região, os alunos observaram que alguns desses lugares são acessíveis para todos frequentarem e outros são cercados e só é possível a entrada com a autorização do proprietário. Retomamos as conversas que tivemos quando consultamos os verbetes rua, praça e cidade e retornamos ao dicionário em busca das definições que ele trazia. Então, conversamos sobre alguns conceitos que envolviam as distinções de público e privado. Encontramos em Rodríguez-Alcalá (2011, p. 249, grifo do autor) a seguinte orientação:

Quando observamos o plano de uma cidade, vemos que esta se apresenta grosso modo, em sua própria configuração arquitetônica, como um quadriculado de espaços privados (casas, edifícios), concebidos como lugares de habitar, do morar (isto é, espaços para fixar-se, assentar-se), circundados por espaços públicos, planificados para circular e encontrar-se (ruas/calçadas, para veículos/pedestres; praças). Essa divisão que envolve questões técnicas e estéticas, entre outras, para o planejamento e construção dos prédios e dos equipamentos urbanos que operacionalizem tais modalidades de moradia e de circulação/encontro, responde a modos de estar-juntos relacionados aos 
próprios sentidos históricos do que seja 'público' ou 'privado'.

Outra questão que reclamava por sentidos durante o trabalho com os mapas é que não podíamos considerar a cidade sem considerar os sujeitos que a constituem. A cidade é o espaço para o desenvolvimento das relações interpessoais. Baldini (2011, p. 57) nos diz que a cidade significa

um corpo imaginariamente construído, com seus limites, seus 'de dentro' (cidadãos) e seus 'de fora' (marginais), suas duplas articulações de sentido (a cidade como o oposto do campo, a cidade como o todo políticoadministrativo); de qualquer modo, como todo corpo, é necessário traçar um fim e um começo, um dentro do corpo e um fora do corpo, um público e um privado, lugares de identificação.

Muitas vezes os alunos identificam-se com a escola, com a igreja, com alguns espaços da cidade, mas não percebiam a cidade, como um espaço de inter-relações. O trajeto casa-escola é a única via, muitas vezes conhecida por esses alunos. Fedatto (2013, p. 36) diz que

[...] a cidade não é vista apenas como um cenário ou um pano de fundo. É um espaço histórico que se edifica no correr do tempo, vai sendo burilado e gasto pela sobreposição de construções e (di)lapidado no andamento de vias e viandantes que intervêm na significação e marcam o corpo dos sentidos. o espaço citadino produz o contíguo, o imediato e o localizado e, nesse gesto, delimita o estranho, o externo e o remoto. 
Como havia pedido aos alunos que trouxessem por escrito os endereços de suas residências, nas aulas, que demandaram bastante tempo, fomos utilizando os mapas das agendas e o mapa maior, afixado no quadro, ao mesmo tempo. Assim, não teriam que apenas aguardar o momento de ir ao quadro localizar o endereço. Eles já iam localizando no mapa menor, de maneira individual ou coletiva e aos poucos, individualmente, iam ao mapa maior. Os alunos foram ao quadro, onde deixei um mapa grande da cidade, e foram fazendo o percurso da escola até suas casas com um barbante. Devido ao mapa ser muito pequeno, o maior que conseguimos na cidade, tivemos certa dificuldade em contornar os caminhos.

Alguns alunos pediram para fazer o percurso que o ônibus faz e o que eles fazem quando estão de bicicleta. Dois alunos não souberem registrar o percurso e foram auxiliados pelos colegas. Interessante analisar a fala de uma aluna, que, ao conversamos sobre as praças da cidade, afirmou que apenas passava perto das praças dos bairros, pois a mãe permitia que ela frequentasse apenas as praças do centro da cidade. Em debate com os outros alunos, que afirmavam que as praças de bairros eram tão interessantes quanto as praças do centro, a aluna afirmou que as praças dos bairros eram frequentadas por pessoas ruins: "bêbados, mendigos e drogados".

Conversamos sobre a questão de praças e logradouros públicos servirem de moradia aos que não tem residência, especialmente nas grandes cidades, e que em alguns desses espaços públicos, também na 
nossa cidade, em virtude da violência urbana, estabiliza o imaginário da aluna. Mas conversamos também que as praças, do centro ou dos bairros, são frequentadas por todos. Em nossa cidade, as praças do centro, recebem por parte do poder público maior cuidado com a iluminação, limpeza e conservação. Os eventos públicos, normalmente, acontecem nas praças do centro, enquanto algumas praças dos bairros, por não receberem os mesmos cuidados, reforçam o imaginário de local perigoso. Rodríguez-Alcalá (2011, p. 252) nos explica que

A questão que se coloca é que um espaço público como a praça, assim com o as ruas e as calçadas, de lugares de circulação e de encontro passam a ser, contemporaneamente, lugares de moradia, de habitação, com a tensão que isso produz em relação tanto à concepção arquitetural do espaço como às normas de sociabilidade estabelecidas. Essas imagens são, nesse sentido, um sintoma de desagregação de fronteiras entre público e privado, resultado de problemas políticos e econômicos mais amplos [...].

As agendas telefônicas foram utilizadas para outras atividades durante o desenvolvimento do projeto pedagógico. Movida pela curiosidade dos alunos, novamente o planejamento foi revisitado e valendo-nos das características das agendas telefônicas que contêm imagens do comércio, slogan, endereços e outras informações, realizamos atividades bastante produtivas. Os alunos selecionaram alguns estabelecimentos, localizaram e apresentavam no mapa maior, explicavam aos outros as atividades desses estabelecimentos comerciais 
bem como a localização, demonstrando intimidade e conhecimento dos locais da cidade, não observados nas primeiras atividades com mapas.

Mobilizamos para o trabalho com as agendas telefônicas os conceitos de memória e imaginário, considerando sua relação com a história e a ideologia. Ao nos depararmos com os slogans da cidade bem como as diversas formas de linguagem, percebemos que não há como não sermos tomados pelas redes de sentidos que, no movimento da história, atualizam memórias, identificam sujeitos e inauguram sentidos. Nunes (1998) salienta que

\begin{abstract}
Construído através de frases feitas, estereótipos, expressões idiomáticas, ditos populares, provérbios, frases de efeito, o slogan atualiza memórias discursivas, reconfigurando-as. Vemos a memória como 'um espaço móvel de divisões, de disjunções, de deslocamentos e de retomadas, de conflitos de regularização... Um espaço de desdobramentos, réplicas, polêmicas e contradiscursos.' (Pêcheux 1985). Consideramos, assim, os slogans como enunciados que, aparecendo como acontecimentos públicos, inscrevem-se na história produzindo efeitos de sentido.
\end{abstract}

Não trabalhamos, especificamente, os sentidos das propagandas ou dos slogans com os alunos, mas ao visualizar as materialidades e as discursividades, os alunos tiveram acesso às diversas possibilidades de leituras. Observando os diversos slogans contidos nas agendas telefônicas, concordamos com a afirmação de Nunes (1998) ao dizer que

O imperativo, assim como o afirmativo, da publicidade é uma marca da constituição do sujeito urbano, imerso num mundo de necessidades lógico-pragmáticas: se você é

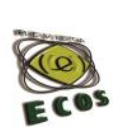


assim, você compra isso; você é assim, portanto você faz isso; este objeto é assim, então ele é a sua cara; acontece isso, logo você fará aquilo. As diversas formas de interpelação dos slogans condicionam a constituição ideológica dos sujeitos nas situações cotidianas. O lugar de enunciação que aí se estabelece tem a ver com a formação histórica do sujeito urbano enquanto sujeito político.

Qualquer objeto simbólico, tomado como discurso, não significa em si mesmo. Todo sentido é em "relação à.” (Canguilhen, 1990, apud Orlandi, 2012). Nos mapas, os discursos atravessam-no, e neles são produzidos discursos. Em Orlandi (2011, p. 21) lemos que

O espaço é delimitado e constituído por relações de poder. E é por isso que significa. Ele tem além de tudo existência política, jurídica e administrativa reconhecidas. Essa é sua materialidade em que o simbólico e o político se conjugam.

Portanto, o espaço é significado pela relação com o poder. É um espaço político. "Tomar o mapa enquanto uma unidade é tomar um texto cujos enunciados são os nomes de rua”. (GUIMARÃES, 2005, p 63). Quando lemos os mapas é possível visualizar a temporalidade e o movimento da cidade. Ao perceberem as transformações geográficas, as expansões territoriais, pela comparação de mapas mais antigos com os mais atuais, os alunos experienciaram o movimento histórico e geográfico da cidade.

Nas leituras dos mapas de Rondônia e Vilhena, juntamente com as explicações que fazíamos com os alunos, em Libras, mostramos nos mapas mais antigos e mapas na internete a formação do estado de 
Rondônia. Este foi um momento forte do trabalho, porque ao contar a história da criação política do estado de Rondônia e os processos de ocupação, os alunos fizeram relação com a história de vida da família deles: histórias vindas de outras regiões.

Também conversamos sobre algumas mudanças percebidas nos mapas da cidade de Vilhena. Não consegui mapas da época da criação do município, mas pela leitura de um mapa integrante de uma lista telefônica de 2002, os alunos puderam comparar com o mapa atual e visualizar o surgimento de seis novos bairros e vários loteamentos.

As atividades com o mapa permitiram aos alunos, pelas leituras desses objetos, observar movimentos históricos e geográficos dos espaços de Vilhena e Rondônia. Eu objetivava com essas atividades que os alunos percebessem o movimento da história e os discursos pelas diversas leituras proporcionadas por essa materialidade. Os alunos puderam observar cidade, a língua e a história.

Ao longo desse projeto buscamos compreender, pelo viés da Análise de Discurso, da Semântica do Acontecimento e da História das Ideias Linguísticas, como as nomeações de lugares da cidade de Vilhena produzem sentidos nos alunos surdos.

É preciso pensar atividades que permitam ao aluno acessar e compreender em Língua Portuguesa. Propus-me a sair da "zona de conforto" de ensinar a "língua imaginária" e aventurar-me pelo aprender, junto aos alunos, pela "língua fluída". Como nos diz Orlandi (2003, p. 10), "É no espaço da diferença que o sujeito se constitui". 
Questões sobre a cidade me tocam profundamente, porque dispõem de propícias e diversas condições de produção para o trabalho com nomeações. Fedatto (2013, p.114) sustenta nosso dizer ao pontuar que

[...] nomear é tomar posição em relação ao objeto, mas a denominação mesma faz esquecer que há um enunciador, um ato, um discurso. a designação de logradouros se mostra, portanto, um campo fecundo que nos permite questionar como as formas da língua convocadas na textualidade dos nomes de rua se relacionam com as condições históricas que as produziram.

Realizamos as atividades com os alunos sempre pensando em trabalhar os deslocamentos e as reconfigurações de lugares de aluno e de professor na relação com o conhecimento nos processos educacionais. Concordamos com os dizeres de Orlandi ao propor que

Trabalhando politicamente a relação dos sujeitos com os sentidos, procuramos aumentar a capacidade de compreensão do leitor, expondo-o a percursos de significação diferentes, abertos, sujeitos a equívocos. Não se trata de dar-lhes novos sentidos, mas de criar condições textuais, materiais para que ele trabalhe a construção de arquivos - discursos documentais de toda ordem - que abram sua compreensão para sentidos outros, mesmo os irrealizados. E isso não se faz por exclusão ou mera ou pela mera quantidade, mas pela observação do que coexiste como textualidade. Já que os sentidos são em 'relação a'. (ORLANDI, 2003, p. 14).

Em nossa incursão teórica, na busca por compreender os sentidos das nomeações de lugares, trabalhamos história e línguas, e a relação entre teoria e prática foi um desafio constante na elaboração desta pesquisa e na realização das atividades. Várias foram as 
expectativas que se abriam antes e durante a realização das atividades, porém, nem todas as atividades planejadas ocorreram conforme eu previa. Diversas outras foram se agregando, quando eu percebia uma possível leitura de um objeto simbólico ou quando me sentia desafiada por algum instigante comentário dos alunos. Concordamos com a posição de Fedatto

\begin{abstract}
perguntando quem, quando, onde, como, por que e analisando o modo pelo qual, através da linguagem, o confronto com a história vai marcando a cidade e reclamando sentidos, podemos problematizar isso que é habitualmente visto como evidência e olhar para as construções urbanas como artefatos simbólicos e políticos que, pela sobreposição de determinados saberes no espaço, intervêm no modo como uma cidade, remetida a um país, significa o imaginário nacional, inaugurando e projetando posições para seus habitantes. (FEDATTO, 2013, p. 27, grifo do autor).
\end{abstract}

No decorrer das atividades, os alunos refletiam, liam, participavam ativamente, sinalizavam, discutiam muito entre eles sobre a formulação de um nome; em outras atividades "silenciavam" mediante as atividades propostas. Em diversas vezes eu ia para sala de aula com um plano pronto, mas sabia que bastava uma das perguntas instigantes e lá ia toda uma aula se reorganizando. Foram muitos os momentos em que um "por que?" se transformava num novo bloco de atividades. Exemplifico com a apresentação de um glossário de nomes próprios que levei para observação dos alunos e, a partir da curiosidade deles, desenvolvemos uma oficina de sinais-nome. 
Outro ponto que merece ser destacado e que consideramos também como imprescindível no trabalho com os alunos surdos é a leitura e escrita da Língua Portuguesa. Compreendemos que "Narrar, contar, descrever, expor, referir, relatar, mostrar, arquivar, transmitir, dizer são atos de linguagem, historiação”. (FEDATTO, 2013, p. 41, grifo do autor). Trata-se de um trabalho que deve realizado ao longo do ano letivo e em todas as demais disciplinas. Considerando as especificidades do projeto e o cronograma previsto, optamos pelo trabalho em Libras, compreendendo que também trabalhamos a Língua Portuguesa.

Dessa maneira, podemos afirmar que alguns dos objetivos traçados no projeto foram redefinidos e, a partir das atividades desenvolvidas, foram contemplados. Dentre esses objetivos, saliento a compreensão do imbricamento de língua e sociedade e as leituras dos mapas, documentários e fotografias como discursos sobre a língua e sobre a história. Conseguimos que os alunos participassem e compreendessem todas as atividades propostas.

A pesquisa possibilitou a abertura de diversas perspectivas de estudos, como o aprofundamento sobre o estudo da cidade, de nomeações, de línguas, estabelecendo relações com o ensino. 


\section{Aulas de Língua Portuguesa em Libras: leitura que se produz}

Diante disso, é que podemos afirmar que uma das maiores contribuições que alcançamos com esse trabalho não foi o glossário em si, mas a possibilidade de leituras que os alunos demonstraram durante todo o percurso. Nas leituras dos mapas, os alunos questionaram (e estudamos) sobre rural e urbano, sobre público e privado, questões históricas e geográficas; ao assistirmos aos documentários sobre a cidade contamos diversas histórias como as de imigração, de ocupações, de povos indígenas entre outras, que perpassando pela linguagem, trouxeram entendimento de que "no processo de constituição de sentidos entram mecanismos de funcionamento discursivo, em que são produzidas, imagens dos sujeitos e dos objetos simbólicos, ocorrem em determinados contextos sócio-históricos" (SILVA, 2009, p. 32).

$\mathrm{O}$ projeto também me instigou a refletir e, ao mesmo tempo, avaliar o meu fazer pedagógico. E foi isso que procurei fazer ao longo desse trabalho: estabelecer esse diálogo da teoria com a prática pedagógica. Nesse sentido, concordamos que

Com o advento da tecnologia digital em sala de aula, o professor deixa de ocupar, junto com o livro didático, a posição de reprodutor do conhecimento, através de quem os alunos têm acesso à 'boa resposta'. Seu papel na relação do aluno com o conteúdo se desloca. Não se trata mais de uma questão de acesso - ele está abundantemente disponível ao aluno e prescinde o professor. Trata-se de, diante da disponibilidade absoluta, guiar a quais buscas levarão a respostas que movem, que deslocam, que educam. Para poder buscar respostas, antes de tudo, é 
preciso ter perguntas. O educador, então, deixa de ter autoridade sobre a 'boa resposta' e, em seu lugar, passa a ter a responsabilidade sobre a 'boa pergunta'. É um papel pautado na criatividade responsável, que viabiliza a articulação dos conhecimentos e dos textos lidos em busca de respostas plurais. Nessa posição, o professor não mais valida sentidos, legitimando o que é verdadeiro, mas coloca em debate as interpretações diante das materialidades significantes. (DE CONTI et al., 2014, p. 63).

Em todo o processo do trabalho com os alunos surdos destaco o ressignificar da minha prática como professora da Língua Portuguesa, para os quem têm o português como primeira língua e para os que, tendo a Libras como primeira língua, aprendem a Língua Portuguesa como segunda língua. Todos nós ensinamos. Todos somos alunos. "Ser diferente é ser diferente". (ORLANDI, 2016, p.33).

\section{Referências}

AUTHIER-REVUZ, Jacqueline. Palavras incertas: as nãocoincidências do dizer. Campinas: Editora da Unicamp, 1998.

BALDINI, Lauro José Siqueira. Cidade e sujeito na rede. In: ORLANDI, Eni P. (Org.). Discurso, espaço e memória: Caminhos da identidade no Sul de Minas. Campinas: RG, 2011. p. 57-68.

FEDATTO, Carolina Padilha. Um saber nas ruas: O discurso histórico sobre a cidade brasileira. Campinas: Editora da Unicamp, 2013.

GUIMARÃES, Eduardo. Semântica do acontecimento: um estudo enunciativo designativo. Campinas: Pontes, 2005. 
NUNES, José Horta. Janelas da cidade: outdoors e efeitos de sentido. In: Escritos. Ver e dizer. n. 2. Campinas, SP: LABEURB/NUDECRI, 1998.

ORLANDI, Eni. Discurso Fundador: a formação do país e a construção da identidade nacional. Campinas: Pontes, 2003.

. Os sentidos de uma estátua: Fernão Dias, individuação e identidade pousoalegrense. In: ORLANDI, Eni (Org.). Discurso, espaço e memória. Campinas: RG, 2011. p. 13-34.

. Ser diferente é ser diferente: a quem interessam as minorias? In: BARROS, Renata Chrystina Bianchi de. CAVALLARI, Juliana Santana (Org.). Sociedade e Diversidade. v. 2. Campinas: Pontes, 2016. p. 19-34.

PFEIFFER, Claudia Castellanos. Compreender discursivamente a escola: uma possibilidade construída. In: RODRIGUES, Eduardo Alves; SANTOS, Gabriel Leopoldino dos; CASTELLO BRANCO, Luiza Katia Andrade. (Org.). Análise de Discurso no Brasil: pensando o impensado sempre. Uma homenagem a Eni Orlandi. Campinas, SP: Editora RG, 2011. p. 231-242.

RODRÍGUEZ, Carolina. Sentido, interpretação e história. In: ORLANDI, Eni (Org.). A leitura e os Leitores. Campinas: Pontes, 2003. p. 47-58.

RODRÍGUEZ-ALCALÁ, Carolina. Discurso e cidade: a linguagem e a construção da "evidência de mundo". In: RODRIGUES, Eduardo Alves; SANTOS, Gabriel Leopoldino dos; CASTELLO BRANCO, Luiza 
Katia Andrade. (Org.). Análise de Discurso no Brasil: pensando o impensado sempre. Uma homenagem a Eni Orlandi. Campinas, SP: Editora RG, 2011. p. 243-258.

SILVA, Marisa Ganança Teixeira da. Outros sentidos para os Galhos Secos. In: BOLOGNINI, Carmen Zink, PFEIFFER, Cláudia Castellanos, LAGAZZI, Suzy. (Org.). Discurso e Ensino: Práticas de linguagem na escola. Campinas: Mercado de Letras, 2009. p. 31-46 